\title{
Development of podophyllotoxin-loaded nanostructured lipid carriers for the treatment of condyloma acuminatum
}

\author{
YAN GAO, KAI HAN, QI WANG, ZHILI HU, QINGXIU LIU, LISHI LIU and KANG ZENG \\ Department of Dermatology, Nanfang Hospital, Southern Medical University, Guangzhou, Guangdong 510515, P.R. China
}

Received October 4, 2017; Accepted January 5, 2018

DOI: $10.3892 / \mathrm{mmr} .2018 .8696$

\begin{abstract}
Condyloma acuminatum (CA) is a common sexually transmitted disease caused by human papillomavirus (HPV). Podophyllotoxin (POD), a cytotoxic compound, is able to effectively treat HPV; however, the severe irritation side effects of POD restrict its use as a treatment for CA. The aim of the present study was to construct novel POD-loaded nanostructured nanolipid carriers (POD-NLCs) and evaluate their physicochemical characteristics and cytotoxicity. POD-NLCs $(0.5 \%)$ were prepared using emulsion-evaporation and low temperature-solidification methods with optimized conditions and preparations. Subsequently, the POD-NLCs were physicochemically characterized and their in vitro and in vivo release efficiencies and in vitro cytotoxicity were studied. The prepared POD-NLCs had an average particle size, $\zeta$ potential, polydispersity index and encapsulation efficacy of $178.5 \pm 20 \mathrm{~nm},-27 \pm 0.5 \mathrm{mV}, 0.18 \pm 0.01$ and $82.9 \pm 2 \%$, respectively. In vitro and in vivo release studies demonstrated that POD-NLCs are able to provide sustained drug delivery for $72 \mathrm{~h}$ in vitro and $10 \mathrm{~h}$ in the mucosa. Compared with a tincture formulation of POD (POD-T), POD-NLC induced less inflammatory cytokine production in the cervical mucous and led to a decreased histopathological score. In addition, a cytotoxicity assay demonstrated that inhibition of the POD-NLCs was $98.4 \%$ at $24 \mathrm{~h}$ and remained $>98 \%$ up to $72 \mathrm{~h}$. Furthermore, more cells were arrested in the G2/M phase of the cell cycle following POD-NLC treatment compared with the POD-T treatment. The present study provides evidence that POD-NLC is a promising delivery system for the treatment of CA.
\end{abstract}

\section{Introduction}

Condyloma acuminatum (CA), also known as genital warts, is a common sexually transmitted disease that causes prolific lesions

Correspondence to: Professor Kang Zeng, Department of Dermatology, Nanfang Hospital, Southern Medical University, 1838 North Guangzhou Avenue, Guangzhou, Guangdong 510515, P.R. China E-mail:npfkzk@126.com

Key words: condyloma acuminatum, podophyllotoxin, podophyllotoxin-loaded nanostructured nanolipid carriers, human papillomavirus, cytotoxicity on the genitalia, perianal area, vagina and cervix; CA is caused by certain types of human papillomavirus (HPV) (1). Nearly all sexually active individuals become infected with HPV at least once during their lifetime (2). In females, HPV infection can result in cervical and vaginal intraepithelial neoplasia $(3,4)$. Therefore, the prevention and treatment of HPV infection is a public health issue.

Podophyllotoxin (POD), a cytotoxic compound extracted from the roots and rhizomes of Berberidaceae, is primarily used as an anti-tumor and anti-viral drug (5). POD tincture (POD-T; $0.5 \%$ ) is commonly used as a first-line agent for the treatment of CA (5). However, the tincture is prepared in alcohol, which can cause severe irritation to the vagina, cervix and other mucosae, limiting its application (6). In addition, epidermal uptake and targeting of POD-T are poor and systemic absorption leads to severe side effects, including gastrointestinal disturbances, thrombocytopenia, leukopenia, abnormal liver function, ataxia and peripheral nerve palsy $(7,8)$. To overcome the side effects of POD-T application on mucosae, it is necessary to develop novel alternative formulations to prolong the local residence time in cervical epithelial cells infected by HPV and reduce cervical irritation and systemic toxicity.

At present, localized delivery of chemotherapeutic drugs to the cervix is used for a number of reasons, including to treat vaginal infections, as contraception and as HIV prevention, with various formulations including gels, creams, suppositories, films and nanoparticle drug carriers (NDCs) available (9). A previous study reported that NDCs improve the physical and chemical properties of drugs, provide sustained, targeted release and reduce systemic absorption (10). Nanostructured lipid carriers (NLCs) are a novel type of NDC developed from solid lipid nanoparticles, in which a solid matrix is blended with a fluid lipid to improve drug loading capacity and release properties (10-12). NLCs are able to adhere to the skin surface and transport drugs in a controlled manner, while causing minimal irritation (13).

In the present study, a POD-NLC formula containing $5 \mathrm{mg} / \mathrm{ml}$ POD was prepared and optimized. Tibetan miniature pigs were selected as an experimental animal model to investigate the absorption and metabolism of POD-NLCs and the mucosal irritation caused by POD-NLCs in the porcine cervix. The physicochemical characteristics of this formula, including particle size, entrapment efficiency and polydispersibility, were evaluated to $0.0005,0.005,0.05,0.5$ and $5 \mu \mathrm{g} / \mathrm{ml}$ with sterile water. The stability of POD-NLCs was investigated at $4^{\circ} \mathrm{C}$ and 
at room temperature $\left(25^{\circ} \mathrm{C}\right)$. The release characteristics were investigated in vitro and in vivo, and cervical mucosal tissue irritation was investigated in vivo. The cytotoxicity of POD-NLCs on VK2/E6E7 cells and cell cycle arrest were also investigated.

\section{Materials and methods}

Chemicals. POD (purity 98\%, high performance liquid chromatography grade, lot no. J1208009) was purchased from Shanghai Aladdin Bio-Chem Technology Co., Ltd. (Shanghai, China). A $5 \mathrm{mg} / \mathrm{ml}$ podophyllotoxin tincture was prepared using $75 \%$ ethanol.

POD loaded NLC preparation. A POD-NLC formula containing $5 \mathrm{mg} / \mathrm{ml}$ [POD-NLC $(0.5 \%)$ ] was prepared using the emulsion-evaporation and low temperature-solidification methods, as previously described (14). The formulation was optimized using orthogonal array testing. Briefly, $50 \mathrm{mg}$ of POD, glyceryl monostearate (Sigma-Aldrich; Merck KGaA, Darmstadt, Germany) and octyl/decyl acid triglyceride (Sigma; Merck KGaA) were dissolved in methylene chloride and lecithin (Sigma; Merck KGaA) was dissolved by sonication in ethanol $(\geq 99.7 \%)$ for $30 \mathrm{~min}$ at $4^{\circ} \mathrm{C}$. Methylene chloride and ethanol solutions were mixed to form an organic phase. Subsequently, the organic phase was rapidly injected into a poloxamer aqueous solution, which was subsequently stirred $(245 \mathrm{x} \mathrm{g})$ in a water bath at $80^{\circ} \mathrm{C}(\mathrm{DF}-101 \mathrm{~S}$; Xingshuo Instrument, Guangzhou, China) for 3-4 h. Subsequently, a coarse emulsion was rapidly mixed with $5 \mathrm{ml}$ of water and ice mixture and sonicated $(245 \mathrm{x} \mathrm{g})$ at $4^{\circ} \mathrm{C}$ for $30 \mathrm{~min}$.

Characterization of $P O D-N L C$. The average particle size, $\zeta$ potential and polydispersity index (PDI) were measured using a Malvern Zetasizer 3000HSA (Malvern Instruments, Ltd., Malvern, UK). All samples were prepared in triplicate. The morphology of the POD-NLCs was observed using transmission electron microscopy (TEM; Tecnai G2 Spirit T12; FEI; Thermo Fisher Scientific, Inc., Waltham, MA, USA). To prepare the sample for TEM examination, $50 \mu 1$ POD-NSC was added into $5 \mathrm{ml}$ ethanol. Following ultrasonic dispersion for $15 \mathrm{~min}$, the dispersion was repeatedly scooped with a carbon film copper net sample for $5 \mathrm{~min}$. Then, the dispersion was oven-dried at $60^{\circ} \mathrm{C}$. The prepared samples was used for TEM examination as follows: accelerating voltage, $120 \mathrm{kV}$; dot resolution, $0.34 \mathrm{~nm}$; line resolution, $0.20 \mathrm{~nm}$; magnification, x50-800,000.

Entrapment efficiency (EE) analysis. EE analysis was carried out as previously described (15). The nanoparticles were isolated using ultrafiltration filters $(0.22 \mathrm{um})$ and centrifuged for $30 \mathrm{~min}$ at $23,128 \mathrm{x} \mathrm{g}$. $\mathrm{W}_{\text {free }}$ is the amount of soluble free drug in the supernatant and $\mathrm{W}_{\text {total }}$ is the amount of drug added to the emulsion. The samples were analyzed in triplicate and assessed using high-performance liquid chromatography (HPLC, without internal standards; LC-20A; Shimadzu Corporation, Kyoto, Japan) with a Ecosil C18 analytical column $(4.6 \times 250 \mathrm{~mm} ; 5 \mu \mathrm{m})$ was used and maintained at $40^{\circ} \mathrm{C}$. The mobile phase contained methanol and glacial acetic acid (52:48, v/v; flow rate, $1 \mathrm{ml} / \mathrm{min})$. The injection volume was $20 \mathrm{ml}$, the retention time was approximately $6 \mathrm{~min}$ and the detection wavelength was $292 \mathrm{~nm}$. The recovery rate ranged from 98.6 to $99.6 \%$. The POD concentration, with a range of $1-500 \mu \mathrm{g} / \mathrm{ml}$ ( $\mathrm{r}=$ correlation coefficient, 0.9995) was measured to detect the POD formulations. The EE was calculated using the following formula: $\mathrm{EE}(\%)=\left[\left(\mathrm{W}_{\text {total }}-\mathrm{W}_{\text {free }}\right) / \mathrm{W}_{\text {total }}\right] \times 100$.

In vitro release studies. The release kinetics of POD-NLC were studied using Franz diffusion cells. Simulated vaginal fluid (SVF) was used as the release medium and was prepared according to a previously described method (16). Briefly, $0.5 \mathrm{ml}$ tested solutions were added into donor chambers and filtered through the cellulose acetate membrane $(0.45 \mu \mathrm{m}$; Beijing Solarbio Science \& Technology Co., Ltd., Beijing, China) and aliquots $(0.1 \mathrm{ml})$ were subsequently withdrawn from receptor chambers at 1, 2, 4, 6, 8, 10, 12, 24, 36, 48, 60, 72,84 and 96 h. Samples were diluted with methanol (99.9\%) six times and assessed by HPLC.

Animal model. A total of 15 female Tibetan mini-pigs (8 months old; $25 \mathrm{~kg}$ ) were purchased from the Center of Experimental Animals, Southern Medical University (Guangzhou, China). The pigs were maintained in large hog pens $(n=7$ per hog pen) in a natural environment $\left(25^{\circ} \mathrm{C}, 12 \mathrm{~h}\right.$ dark cycle) with free access to food and water. All the experimental animals and the protocol (permit number for pigs: 44002100008963) used in the present study were approved by the Experimental Animal Ethics Committee of the Southern Medical University (Guangzhou, China).

In vivo drug release studies in cervical mucosal tissue and cervical mucus. For the purpose of dynamics analysis, 15 female Tibetan mini-pigs were randomly divided into four subgroups and administrated with 1, 5 and $20 \mathrm{mg} / \mathrm{ml}$ POD-T, and $5 \mathrm{mg} / \mathrm{ml}$ POD-NLC. Cervical secretions were extracted from ophthalmic sponges using a previously described method (17); 1,5 and $20 \mathrm{mg} / \mathrm{ml}$ POD-T, and $5 \mathrm{mg} / \mathrm{ml}$ POD-NLC $(0.5 \mathrm{ml})$ were administrated on the cervix for one treatment. Cervical mucus was collected at 2, 4, 6, 8 and $10 \mathrm{~h}$ using sponges held in the cervix and left to stand for $5 \mathrm{~min}$ as previously described (18). All sponges were transferred immediately into sterile tubes and stored at $-20^{\circ} \mathrm{C}$. Following anesthesia, cervical mucosal tissue was collected by means of a simple punch biopsy as previously described method (19) at $2,4,6,8,10 \mathrm{~h}$ following administration of 1,5 and $20 \mathrm{mg} / \mathrm{ml}$ POD-T, and $5 \mathrm{mg} / \mathrm{ml}$ POD-NLC $(0.5 \mathrm{ml})$ as previous stated, and the coated cervical mucosa determined to was $3.14 \mathrm{~cm}^{2}$. Subsequently, tissues were rinsed with normal saline and stored at $-20^{\circ} \mathrm{C}$. POD was extracted from the sponge and cervical tissue by homogenization in $1.0 \mathrm{ml}$ methanol followed by centrifugation $\left(24,573 \mathrm{x}\right.$ g for $15 \mathrm{~min}$ at $\left.4^{\circ} \mathrm{C}\right)$.

Cell culture. The immortalized vaginal epithelial cells VK2/E6E7 (ATCC ${ }^{\circledR}$ CRL-2616 ${ }^{\mathrm{TM}}$ ) were cultured in Dulbecco's modified Eagle's medium (DMEM; Gibco; Thermo Fisher Scientific, Inc.) supplemented with $10 \%$ fetal bovine serum (FBS; HyClone; GE Healthcare Life Sciences, Logan, UT, USA) at $37^{\circ} \mathrm{C}$ in an atmosphere containing $5 \% \mathrm{CO}_{2}$.

Histopathological detection and evaluation of cervical mucous irritation. For the cervical mucous irritation study, 
15 female pigs were randomly assigned to 5 subgroups and administered with the following treatments: i) Normal saline (0.5 ml/day; $\mathrm{n}=3)$; ii) $5 \mathrm{mg} / \mathrm{ml}$ POD-NLC (0.5 ml/day; $\mathrm{n}=3)$; iii) $5 \mathrm{mg} / \mathrm{ml}$ POD-NLC (1 ml/day; $\mathrm{n}=3)$; iv) $5 \mathrm{mg} / \mathrm{ml}$ POD-NLC ( $2 \mathrm{ml} /$ day; $\mathrm{n}=3)$; and v) $5 \mathrm{mg} / \mathrm{ml}$ POD-T (0.5 ml/day; $\mathrm{n}=3)$. Following catheterization via an insemination catheter (20), treatments were administered for 3 consecutive days (once daily for three days in total). The method of transcervical administration was adopted as previously described (21). Pigs were observed daily for clinical signs, including swelling, redness, erosion and vaginal discharge. Cervical secretions of the pigs were collected using ophthalmic sponges as previously described (18). Porcine-specific interleukin (IL)-1 $\beta$, -6 and -8 levels in the cervical mucus prior to and following 24, 48 and $72 \mathrm{~h}$ drug administration were measured using a Luminex instrument (Luminex 200; Luminex Corporation, Austin, TX, USA) and immuno assays (ProcartaPlex Porcine Basic kit, EPX010-60460-901; ProcartaPlex Porcine IL-1 beta Simplex, EPX01A-66048-901; ProcartaPlex Porcine IL-8 (CXCL8) Simplex, EPX01A-66052-901 and ProcartaPlex Porcine IL-6 Simplex, EPX01A-66051-901; all Thermo Fisher Scientific, Inc.). On day 4, cervical tissues (obtained by single punch biopsy) were cut into 6-mm sections using a slicer RM2235 (Leica Microsystems GmbH, Wetzlar, Germany), and then fixed in $10 \%$ neutral-buffered formalin (Beijing Solarbio Science \& Technology Co., Ltd.) followed by hematoxylin-eosin (Beijing Solarbio Science \& Technology Co., Ltd.) staining (hematoxylin for $20 \mathrm{~min}$ and eosin for $5 \mathrm{~min}$, each at $25^{\circ} \mathrm{C}$ ) and complete examination under a light microscope (BX-41-32H02; Olympus Corporation, Tokyo, Japan; magnification, $\mathrm{x} 10)$. The pathological scoring of mucosae was completed by two blinded professional pathologists using a previously described method with the following evaluation criteria: $0=$ absent, $1=$ minimal, $3=$ moderate, $4=$ marked (22).

Evaluation of inhibition of proliferation. POD-NLC-induced inhibition of cell proliferation was tested using VK2/E6E7 cells. Following attaching for $24 \mathrm{~h}$, cells were exposed to a series of doses $(0.0005,0.005,0.05,0.5$ and $5 \mathrm{mg} / \mathrm{ml})$ of POD-NLC or POD, which was diluted with sterile water. The control group contained only the culture medium. Following incubation for 24, 48 and 72 h, $10 \mu \mathrm{l}$ Cell Counting kit-8 (CCK-8) solution (Dojindo Molecular Technologies, Inc., Kumamoto, Japan) was added to each well of the plate followed by incubation at $37^{\circ} \mathrm{C}$ for $4 \mathrm{~h}$. The absorbance was measured at a wavelength of $450 \mathrm{~nm}$ using a Microplate Luminometer (Turner Designs, Sunnyvale, CA, USA). All experiments were repeated three times. The proliferation inhibition ratio of cells was calculated using the following formula: Inhibition ratio $=[1-\mathrm{A}(\mathrm{POD}$ or POD-NLC group)/A(control group)] $x 100 \%$, where $\mathrm{A}$ is the absorbance value at a wavelength of $450 \mathrm{~nm}$.

Apoptosis assay. Cell apoptosis was detected using the Annexin V-fluorescein isothiocyanate (FITC) kit (containing binding buffer, Annexin V-FITC and propidium iodide; BD Biosciences, Franklin Lakes, NJ, USA) according to a previously described method (23). Briefly, $1 \times 10^{6} \mathrm{VK} 2 / \mathrm{E} 6 \mathrm{E} 7$ cells were incubated with POD or POD-NLC at a dose of $0.05 \mu \mathrm{g} / \mathrm{ml}$ for $48 \mathrm{~h}$. Cells were subsequently harvested and re-suspended in PBS. The cells were counted and $1.5 \times 10^{5}$ cells were re-suspended in $200 \mu \mathrm{l}$ binding buffer and $5 \mu \mathrm{l}$ Annexin V-FITC, and stained for $10 \mathrm{~min}$ at room temperature. The cells were centrifuged $\left(120 \mathrm{x} \mathrm{g}\right.$ for $5 \mathrm{~min}$ at $\left.28^{\circ} \mathrm{C}\right)$ and re-suspended with $200 \mu \mathrm{l}$ binding buffer and then added $10 \mu \mathrm{l}$ propidium iodide (PI) and stained for $5 \mathrm{~min}$ on ice. Finally, the stained cells were analyzed using a NovoCyte flow cytometer (ACEA Biosciences, San Diego, CA, USA). Data were analyzed with NovoExpress software (version 1.2.4; ACEA Biosciences).

Cell cycle analysis. VK2/E6E7 cells $\left(1 \times 10^{6}\right)$ incubated with POD or POD-NLC at a dose of $0.05 \mu \mathrm{g} / \mathrm{ml}$ for $48 \mathrm{~h}$ were harvested by centrifuged $\left(120 \mathrm{x} \mathrm{g}\right.$ for $5 \mathrm{~min}$ at $\left.28^{\circ} \mathrm{C}\right)$ then washed twice with cold PBS. Following fixing with $75 \%$ ethanol for $24 \mathrm{~h}$ at $4^{\circ} \mathrm{C}$, the cells were washed twice with PBS and stained with $300 \mu \mathrm{l} \mathrm{PI}(100 \mathrm{~g} / \mathrm{ml})$ for $30 \mathrm{~min}$ at $4^{\circ} \mathrm{C}$ in the dark. The cell cycle was analyzed using a NovoExpress software (version 1.2.4; ACEA Biosciences) and the percentage of cells in each phase was calculated with the ModFit LT5.0 software (Verity Software House, Topsham, ME, USA).

Hoechst 33342 staining. $1 \times 10^{6}$ VK2/E6E7 cells incubated with POD or POD-NLC at a dose of $0.05 \mu \mathrm{g} / \mathrm{ml}$ for $48 \mathrm{~h}$ were fixed in $4 \%$ paraformaldehyde (Beyotime Institute of Biotechnology, Beijing, China) for $15 \mathrm{~min}$ at room temperature. Subsequently, the cells were stained with Hoechst 33342 (Beyotime Institute of Biotechnology) for $15 \mathrm{~min}$ at room temperature; cells were photographed by the fluorescence microscopic examination with $350 \mathrm{~nm}$ excitation wavelength (BX-41-32H02; Olympus Corporation, magnification, $\mathrm{x} 20$ ).

Statistical analysis. The experimental groups were compared with the control groups via one-way analysis of variance with repeated measures and the Fisher's Least Significant Difference. $\mathrm{P}<0.05$ was considered to indicate a statistically significant difference. Data are presented as the mean \pm standard error of the mean. All calculations were performed using SPSS software (version 19.0; IBM Corp., Armonk, NY, USA).

\section{Results}

Characterization of $P O D-N L C$. In the present study, $0.5 \%$ POD-NLC was prepared using emulsion-evaporation and low temperature-solidification methods. The POD-NLCs were spherical or ellipsoidal (Fig. 1A) and the mean particle size was $178.5 \pm 20 \mathrm{~nm}$ (Fig. 1B) with a PDI of $0.18 \pm 0.01$ (data not shown), which implies that the prepared POD-NLCs were monodisperse. The $\zeta$ potential was $-27 \pm 0.5 \mathrm{mV}$ (Fig. 1C), and the $\mathrm{pH}$ was $6.20 \pm 0.04$ (Table I). The preparation's entrapment efficiency were calculated using the following formula: $\mathrm{EE}(\%)=\left[\left(\mathrm{W}_{\text {total }}-\mathrm{W}_{\text {free }}\right) / \mathrm{W}_{\text {total }}\right] \times 100$. The POD entrapment efficiency in the nanoparticles was determined to be $82.9 \pm 2 \%$ by HPLC (Table I). The final results showed POD-NLC $(5 \mathrm{mg} / \mathrm{ml})$ has a really high entrapment efficiency. The POD-NLC formulation was stable when stored at $4^{\circ} \mathrm{C}$ for 6 months or at room temperature for 3 months, with no stratification, sedimentation or POD crystallization observed.

POD-NLCs sustain drug release and extend the local action time in vitro and in vivo. To investigate the release of 
Table I. Podophyllotoxin-nanostructured lipid carriers (5 mg/ml).

pH Polydispersity index Entrapment efficiency (\%)

\begin{tabular}{llll}
\hline A & 6.22 & 0.187 & 84.90 \\
B & 6.16 & 0.168 & 80.90 \\
C & 6.23 & 0.184 & 83.00 \\
\hline
\end{tabular}

POD-NLCs in vitro, the medium was collected from Franz diffusion cells following POD-NLC and POD-T treatment and analyzed using HPLC. At $6 \mathrm{~h}$ following treatment, nearly $69 \%$ of POD was released from POD-T, compared with $8.8 \%$ from POD-NLCs (Fig. 2A). At 24 h following treatment, 30.98\% of the encapsulated POD was released from POD-NLCs and $64.90 \%$ was released following 72 h (Fig. 2A). Furthermore, in vivo release studies were performed with cervical mucus and mucosal tissues. The results demonstrated that the concentration of POD in cervical mucus, released from the POD-NLC (5 $\mathrm{mg} / \mathrm{ml})$ formulation, decreased gradually following administration but increased compared with the POD-T (5 mg/ml) group at each time point and increased compared with the POD-T $(20 \mathrm{mg} / \mathrm{ml})$ group at $4 \mathrm{~h}(115.3 \mathrm{vs} .95 .8 \mu \mathrm{g} / \mathrm{ml}$, respectively; $\mathrm{P}<0.05)$. The $\mathrm{POD}-\mathrm{NLC}$ group maintained an increased concentration at $10 \mathrm{~h}$ compared with POD-NLC group (189.6 vs. $34.2 \mu \mathrm{g} / \mathrm{ml}$; Fig. 2B). In the cervical mucosal tissue, POD-T administrations at different concentrations (1, 5 and $20 \mathrm{mg} / \mathrm{ml}$ ) reached the maximum concentration of POD $4 \mathrm{~h}$ following administration, followed by a decline. In the $5 \mathrm{mg} / \mathrm{ml}$ POD-NLC group, however, the POD concentration in the cervical mucosal tissue continued to increase up to $8 \mathrm{~h}$ following administration. At $10 \mathrm{~h}$ following administration, the POD concentration in mucosal tissues was not markedly elevated in the $5 \mathrm{mg} / \mathrm{ml}$ POD-NLC group compared with the $5 \mathrm{mg} / \mathrm{ml}$ POD-T group (Fig. 2C). These results demonstrated that, compared with POD-T administration, the POD-NLC exhibited a more sustained release of POD, which may extend the local action time in vitro and in vivo.

POD-NLC prevents injury and inflammatory cytokine production in the cervical mucosal tissue compared with $P O D-T$. Following administration of the formulations, damage to the cervical mucosa was assessed for $72 \mathrm{~h}$. In the low-dose POD-NLC group $(0.5 \mathrm{ml} /$ day $)$, the cervical mucosal epithelium consisted of 5-10 layers of cells with structural integrity. Ulcers and hemorrhaging with neutrophil and mononuclear cell infiltrations were observed in the high-dose POD-NLC and POD-T groups. In addition, necrosis of the mucosal epithelium was observed in the POD-T group (Fig. 3A). In the lamina propria of the cervical mucosal tissue, no inflammatory infiltration was observed in the low-dose POD-NLC group (Fig. 3A-g), whereas a large number of infiltrating neutrophils and mononuclear cells were observed in the high-dose POD-NLC and POD-T groups (Fig. 3A-i and -j, respectively). Furthermore, submucosal vessels in the low-dose POD-NLC group appeared normal (Fig. 3A-l); however, in the high-dose POD-NLC group, capillary congestion, hemorrhaging and infiltration of mononuclear cells into the perivascular region were observed. In the POD-T group, thrombosis of partial vessels occurred (Fig. 3A-o). Histopathological scores were calculated by assessing the results in multiple regions of the cervical mucosal tissue. Histopathological scores of the low-dose and medium-dose POD-NLC group were significantly lower compared with the POD-T group $(4.3 \pm 0.8$ vs. $29.3 \pm 29.3 ; \mathrm{P}<0.05)$. No significant difference was observed between the low-dose POD-NLC and saline groups $(4.3 \pm 0.8$ vs. $3.3 \pm 1.0$; P>0.05; Fig. 3B). Furthermore, the levels of IL-6, -8 and $-1 \beta$ were significantly lower in the low-dose POD-NLC group compared with the high-dose group $(\mathrm{P}<0.01)$, and were not significantly different compared with the NS group (Fig. 3C-E). The levels of inflammatory cytokines in the POD-T group were significantly increased compared with the low-medium- and high-dose POD-NLC groups (Fig. 3C-E). Taken together, these results demonstrate that POD-NLCs cause less injury and inflammatory cytokine production in the cervical mucosal tissue compared with POD-T.

POD-NLC inhibits the proliferation of VK2/E6E7 cells. To evaluate the CA-inhibitory activity of POD-NLCs, the effect of POD-NLC on the proliferation of VK2/E6E7 cells was investigated. Compared with POD, POD-NLC resulted in decreased cell viability at high concentration $(0.5$ and $5 \mu \mathrm{g} / \mathrm{ml})$. The proliferation inhibition rate of VK2/E6E7 cells treated with POD-NLC reached $99 \%$ at a dose of $5 \mu \mathrm{g} / \mathrm{ml}$ (Fig. 4A). However, the inhibition of POD was $64.5 \%$ at a dose of $5 \mu \mathrm{g} / \mathrm{ml}$ and did not increase further with prolonged exposure time (Fig. 4B). The inhibition of POD-NLCs reached $98.4 \%$ at $24 \mathrm{~h}$ and persisted at $>98 \%$ from 24 to $72 \mathrm{~h}$ (Fig. 4B), which is increased compared with the POD treatment group.

Hoechst 33342 staining was performed to assess the morphology of the nuclei (Fig. 4C). It was determined that POD-NLC-treated VK2/E6E7 cells had apoptotic morphology, including cell membrane shrinkage, cell shedding and chromatin condensation. POD-treated cells exhibited a similar pattern (Fig. 4C). In the POD-NLC- and POD-treated groups, the apoptosis rates increased by 13.2 and $7.9 \%$, respectively, compared with the control group (Fig. 4D). Cell cycle distribution was analyzed using flow cytometry. Following treatment for $48 \mathrm{~h}, \mathrm{VK} 2 / \mathrm{E} 6 \mathrm{E} 7$ cells in the POD- and POD-NLC-treated groups were predominantly in the $\mathrm{G} 2 / \mathrm{M}$ phase, and fewer cells were observed in the G0/G1 phase (Fig. 4E). POD-NLC treatment induced $\mathrm{G} 2 / \mathrm{M}$ arrest to a greater extent compared with the POD treatment $(0.863 \pm 0.085$ vs. $0.602 \pm 0.043$, respectively; $\mathrm{P}<0.01$; Fig. 4E). Collectively, these results demonstrate that POD-NLC has a more prominent effect on VK2/E6E7 cell viability compared with the POD treatment.

\section{Discussion}

POD-T $(0.5 \%)$ has been reported to be an effective initial drug for the treatment of CA (24). However, it has been demonstrated to cause severe irritation when applied to the vagina, cervix or other mucosae (25). Recently, POD-NLCs have been proposed as an attractive delivery system for the treatment of HPV and associated diseases with low systemic adverse effects $(14,15)$. Previous studies have reported that nanoparticles of small diameter $(<100 \mathrm{~nm})$ would be more likely to be hindered or immobilized by cervical mucus compared with nanoparticles of larger diameter $(200 \mathrm{~nm})(26,27)$. In the present study, 
A

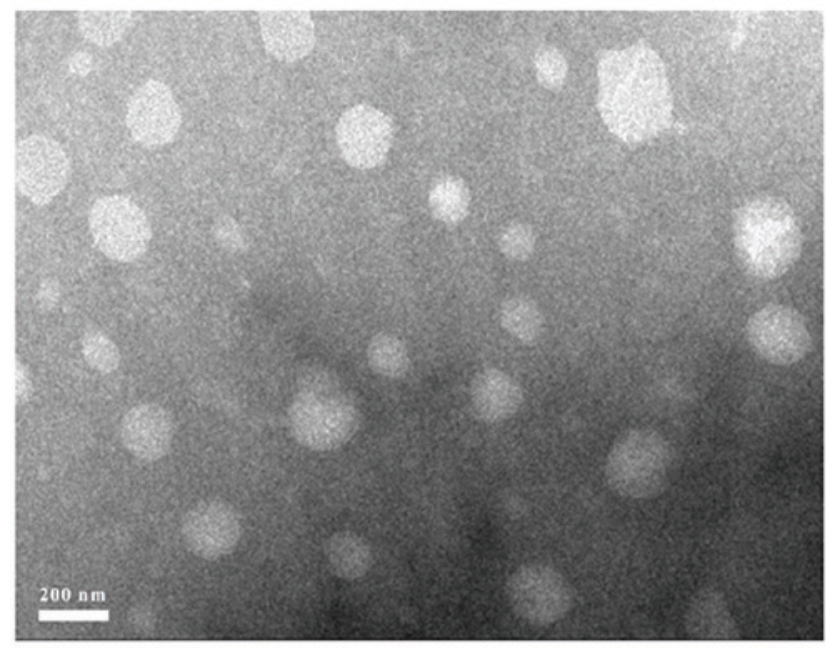

B

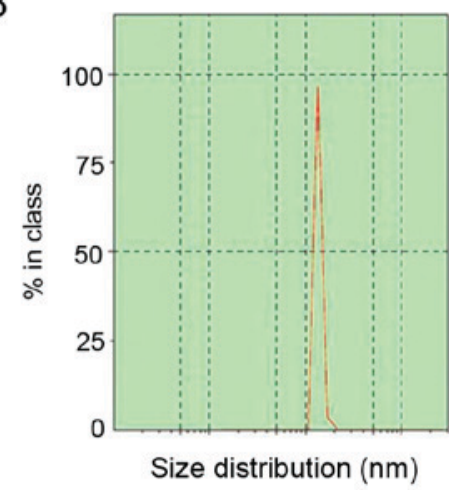

C

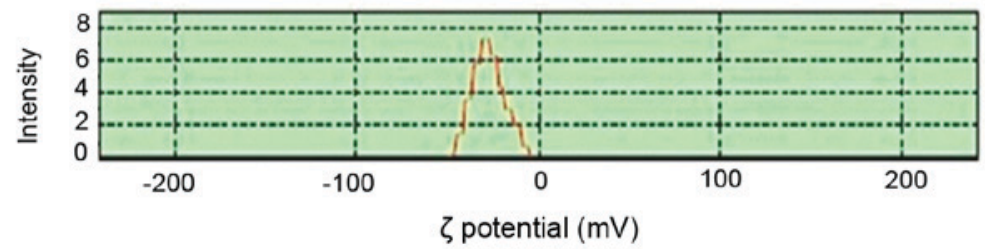

Figure 1. The characterization of $0.5 \%$ POD-NLC. (A) The morphology of the POD-NLCs was observed using transmission electron microscopy (magnification, $x 50,000$ ). (B) The average particle size of $0.5 \%$ POD-NLC was measured by Malvern Zetasizer $3000 \mathrm{HSA}$. (C) The $\zeta$ potential of $0.5 \%$ POD-NLC was measured by Malvern Zetasizer 3000HSA. POD-NLC, podophyllotoxin-loaded nanostructured nanolipid carriers.
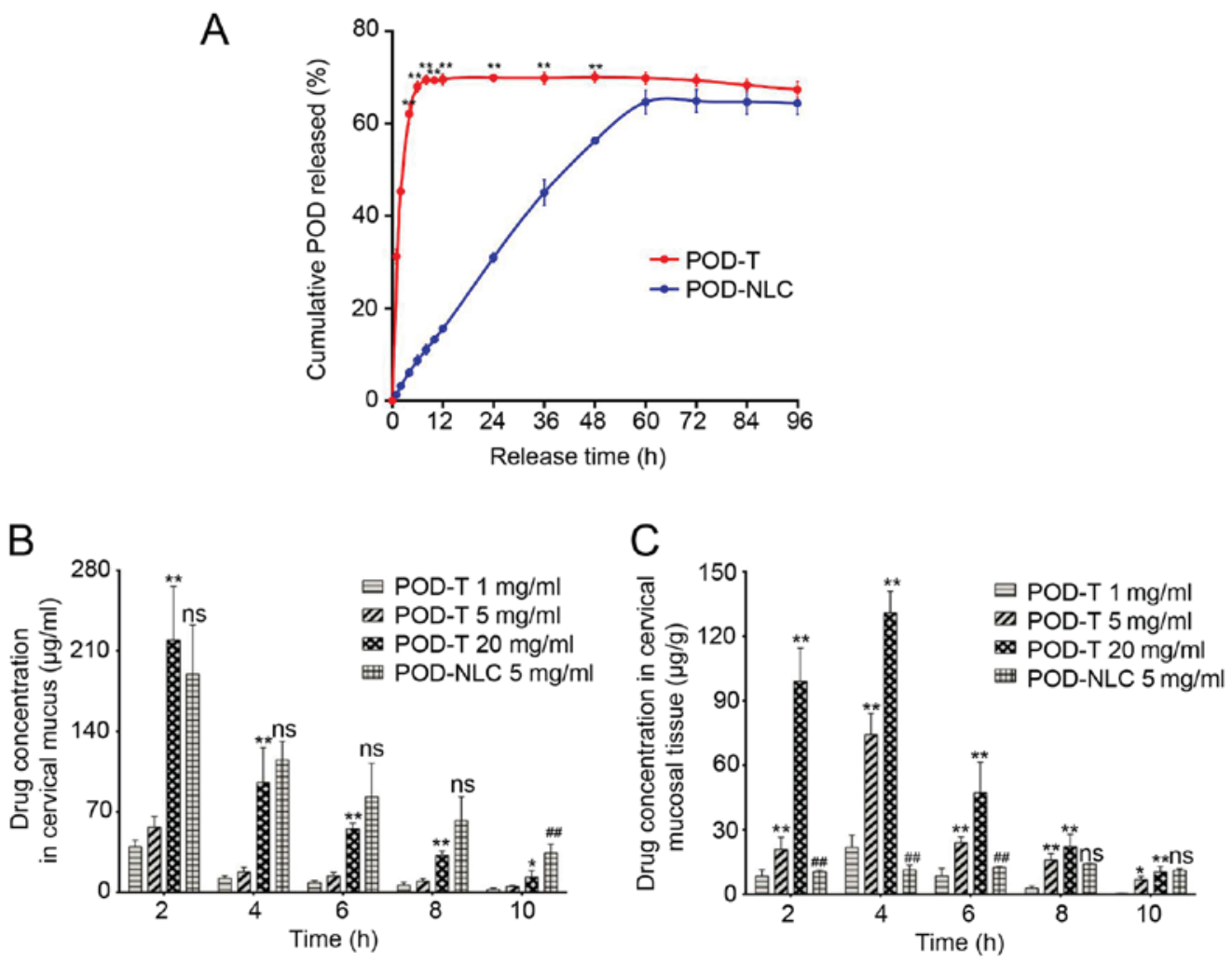

Figure 2. POD-NLC sustains the release of the drug and extends the local action time in vitro and in vivo. (A) In vitro POD release profiles of $0.5 \%$ POD-NLC and $0.5 \%$ POD-T in simulated vaginal fluid. The release kinetics of POD-NLC were studied using Franz diffusion cells ( $\mathrm{pH} 4.2$ at $37 \pm 0.5^{\circ} \mathrm{C}$ ). The cumulative release rate of POD was detected at 1, 2, 4, 6, 8, 10,12, 24, 36, 48, 60, 72, 84 and 96 h. (B) The concentrations of POD in cervical mucus treated with POD-NLC $(5 \mathrm{mg} / \mathrm{ml})$ and different concentrations $(1,5$ and $20 \mathrm{mg} / \mathrm{ml})$ of POD-T, were detected at 2, 4, 6,8 and $10 \mathrm{~h}$. (C) Concentration of POD in cervical mucosa treated with POD-NLC $(5 \mathrm{mg} / \mathrm{ml})$ and different concentrations $(1,5$, and $20 \mathrm{mg} / \mathrm{ml})$ of POD-T, were detected at 2, 4, 6, 8 and $10 \mathrm{~h} .{ }^{*} \mathrm{P}<0.05,{ }^{* *} \mathrm{P}<0.01 \mathrm{vs}$. the POD-T $(1 \mathrm{mg} / \mathrm{ml})$ group; ns, no significant difference vs. the POD-T $(20 \mathrm{mg} / \mathrm{ml})$ group; ${ }^{\# \#} \mathrm{P}<0.01$ vs. the POD-T $(20 \mathrm{mg} / \mathrm{ml})$ group. POD-NLC, podophyllotoxin-loaded nanostructured nanolipid carriers. 
A
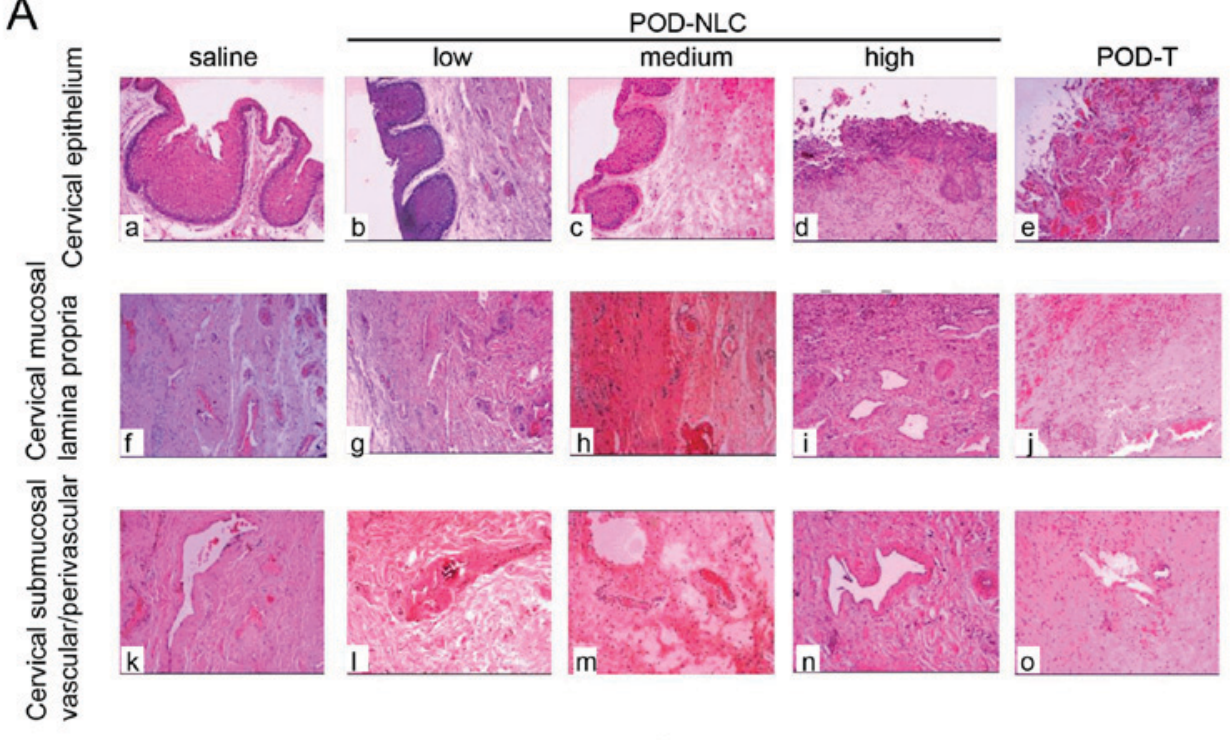

B
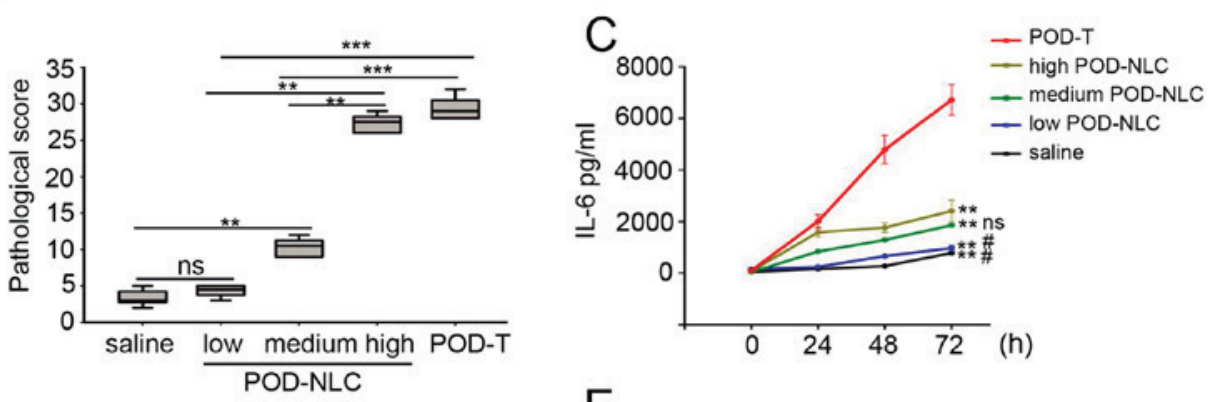

D
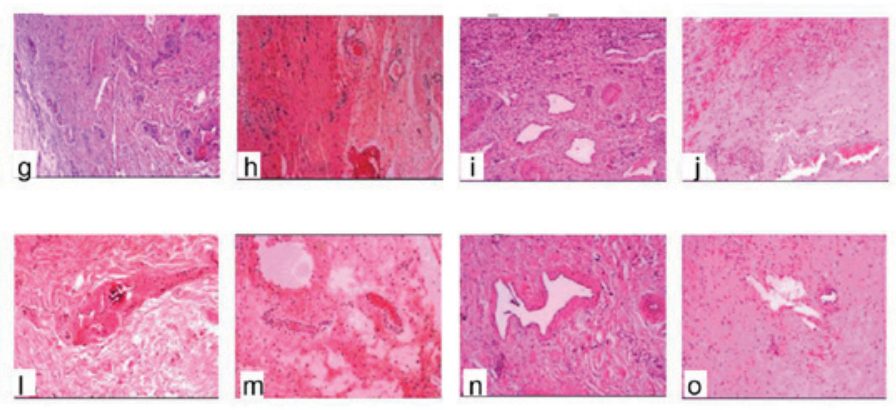

E
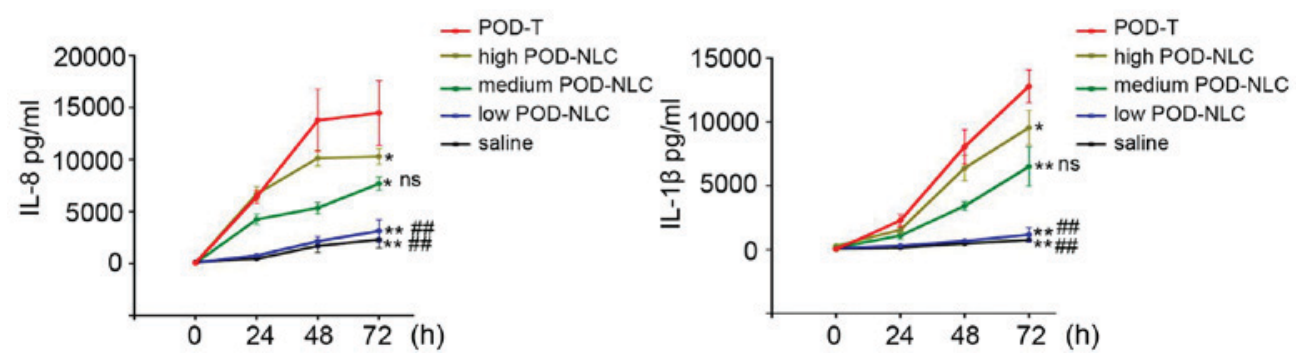

Figure 3. POD-NLC causes decreased injury and expression of inflammatory cytokines in cervical mucous. (A) Histological alterations of the cervical mucosa following treatment with $0.5 \mathrm{ml}$ normal saline (a, f and $\mathrm{k}$ ), $0.5 \mathrm{ml} 0.5 \%$ POD-NLC (b, g and 1), $1.0 \mathrm{ml} \mathrm{0.5 \%} \mathrm{POD-NLC} \mathrm{(c,} \mathrm{h,} \mathrm{and} \mathrm{m),} 2.0 \mathrm{ml} 0.5 \%$ POD-NLC $(\mathrm{d}, \mathrm{i}$ and $\mathrm{n}$ ) and $0.5 \mathrm{ml}$ 0.5\% POD-T (e, j, and o) were detected by hematoxylin and eosin staining (magnification, $\mathrm{x} 40)$. (B) Histopathological score of cervical mucosa treated with $0.5 \mathrm{ml}$ normal saline, $0.5 \mathrm{ml} 0.5 \%$ POD-T and $0.5 \%$ POD-NLC at different doses $(0.5$, 1.0 and $2.0 \mathrm{ml})$. ns, no significant difference; ${ }^{* *} \mathrm{P}<0.01$ and ${ }^{* * *} \mathrm{P}<0.0001$. Concentrations of inflammatory cytokines in cervical secretions were detected by Luminex instrument at 24,48 and $72 \mathrm{~h}$ following treatment. The concentrations of (C) IL-6, (D) IL- 8 and (E) IL-1 $\beta$ were detected in cervical secretions of pigs treated with $0.5 \mathrm{ml}$ normal saline, $0.5 \mathrm{ml} 0.5 \%$ POD-NLC, $1.0 \mathrm{ml}$ 0.5\% POD-NLC, $2.0 \mathrm{ml} 0.5 \%$ POD-NLC and $0.5 \mathrm{ml} 0.5 \%$ POD-T, respectively. ${ }^{*}<<0.05$ and ${ }^{* *} \mathrm{P}<0.01$ vs. the POD-T group. ns, no significant difference; ${ }^{~} \mathrm{P}<0.05$ and ${ }^{\# \#} \mathrm{P}<0.01$ vs. high-dose POD-NLC group. POD-NLC, podophyllotoxin-loaded nanostructured nanolipid carriers; IL, interleukin.

$0.5 \%$ POD-NLCs were prepared with an average diameter of $178.5 \pm 20 \mathrm{~nm}$, which is within the optimal range for mucosal drug delivery.

The mucosae of the reproductive tract secrete appropriate amounts of mucus, mainly composed of mucins, which are responsible for mucoadhesion and elasticity (28). Ramineni et al (29) proposed that the characteristics of mucus could cause it to act as a barrier limiting drug penetration. Additionally, the retention time of traditional formulations (including solutions, suspensions and emulsions) in the reproductive tract surface is insufficient, making it difficult to achieve the desired therapeutic effect (30). Nanoparticles with mucoadhesive properties have previously been used to facilitate drug administration to the mucosa and improve the active effects of transmucosal administration (31). In the present study, in vitro experimentation indicated that the residence time of POD-NLCs was increased compared with POD-T. POD-NLCs enable sustained drug delivery for $60 \mathrm{~h}$, consistent with results of a previous study, which used POD-NLCs for targeted drug delivery (12). In the present study, the in vivo drug release from POD-NLCs in Tibetan miniature pigs was monitored by detecting the amount of POD in the cervical mucus and mucosal tissue. The results demonstrated that the concentration of POD in the mucus of the POD-T group decreased rapidly following transmucosal administration. The amount of POD in the mucus and the mucosal tissue was increased in the POD-NLC group compared with the POD-T group. This demonstrates that, although POD-T penetrates 

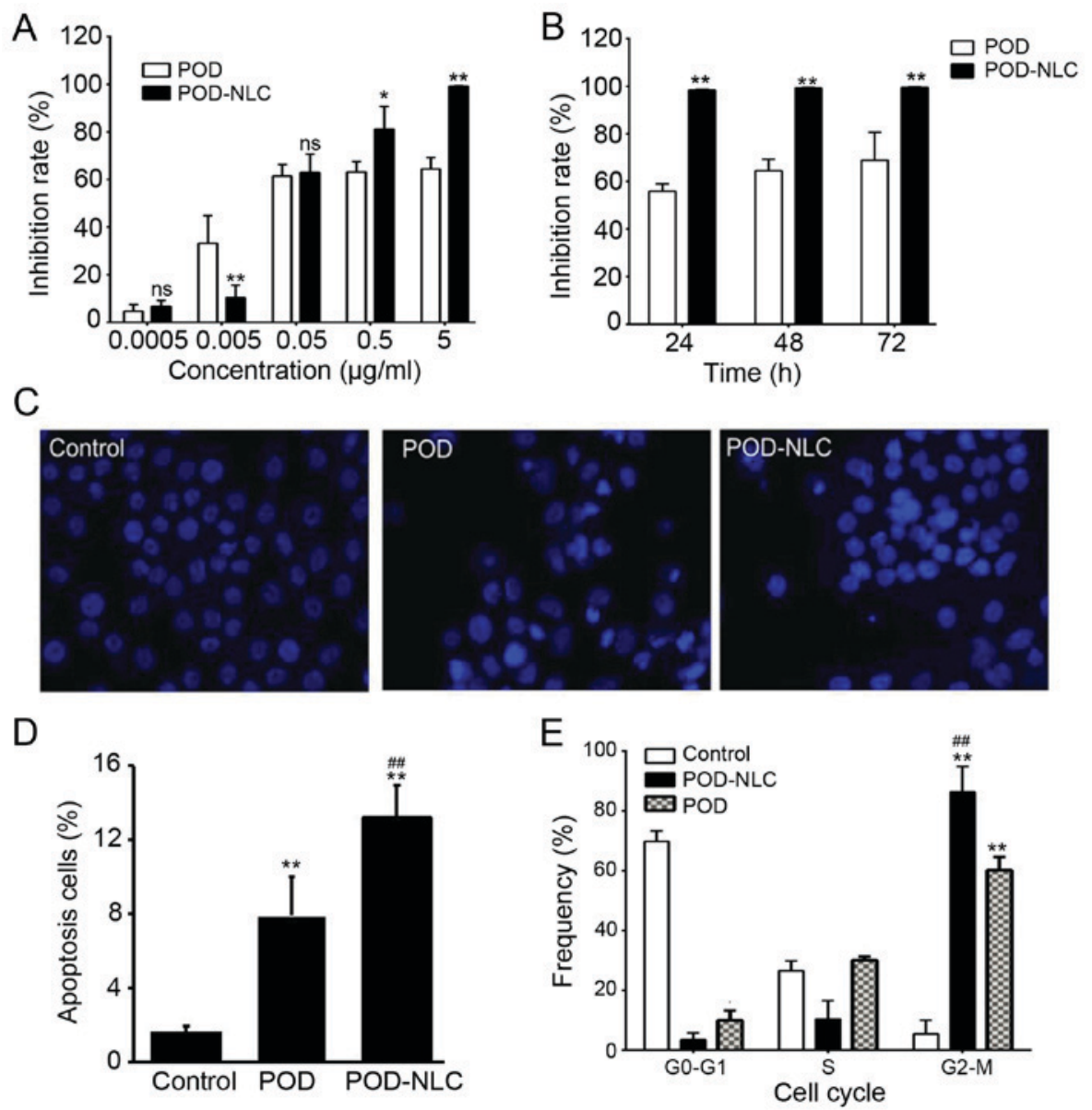

Figure 4. POD-NLC inhibits cell proliferation in VK2/E6E7 cells. (A) Comparison of inhibitory effects of different concentrations of POD-NLC and free-POD following $48 \mathrm{~h}$ of treatment. Ns, no significant difference vs. POD group; ${ }^{*} \mathrm{P}<0.05$ and ${ }^{* *} \mathrm{P}<0.01$ vs. corresponding POD group. (B) Comparison of inhibitory effects of $5 \mu \mathrm{g} / \mathrm{ml}$ POD-NLC and free-POD-T following 24, 48 and $72 \mathrm{~h}$ of treatment. ${ }^{* *} \mathrm{P}<0.01$ vs. the POD group. (C) Morphological alterations of VK2/E6E7 cells incubated with normal saline (control), $0.05 \mu \mathrm{g} / \mathrm{ml}$ POD-NLC or $0.05 \mu \mathrm{g} / \mathrm{ml}$ POD for $48 \mathrm{~h}$ were observed by a fluorescence microscopy (Hoechst 33342 ; magnification, x400). (D) The total number of apoptotic cells and the percentage of the late and early apoptotic cells were quantified. (E) Percentage of VK2/E6E7 cells in different phases of the cell cycle. The number of VK2/E6E7 cells in the G0-G1, S and G2-M phases and the corresponding percentage values were calculated for normal saline, $0.05 \mu \mathrm{g} / \mathrm{ml}$ POD-NLC and $0.05 \mu \mathrm{g} / \mathrm{ml}$ POD-T groups following $48 \mathrm{~h}$ of treatment. ${ }^{* *} \mathrm{P}<0.01 \mathrm{vs}$. the control (normal saline) group; ${ }^{\# \#} \mathrm{P}<0.01$ vs. the $\mathrm{POD}$ group.

the mucus and mucosa more rapidly, POD-NLCs are able to persist in the cervical mucus and on the mucosal surface and exhibit sustained-release for $10 \mathrm{~h}$ and controlled-release properties as high levels of POD were maintained. These results suggest that POD-NLCs possesses mucoadhesive abilities and provides controlled drug release, which is more suitable for the treatment of CA through the cervical mucosal tissue compared with POD-T.

Previous reports have demonstrated that certain antimicrobial agents used in the female reproductive tract can cause damage to the mucosal barrier; drugs that alter the reproductive tract mucosal tissue environment and disrupt this barrier can increase the risk of infection by sexually transmitted pathogens, including human immunodeficiency virus (HIV), HPV and Chlamydia trachomatis (32-34). When the cervical mucosal tissue is stimulated, induced epithelial cell hyperactivity leads to the release of a series of chemokines and cytokines, eliciting an immune response through the transmission of signals to submucosal cells and tissues (24). Cytokines, including IL-1 $\beta$, IL- 8 and IL- 6 , are used as markers for the potential toxicity of drugs administered to the reproductive tract mucosa (20). NLCs can be prepared using both solid and liquid lipids, which induce minimal skin irritation (35). In the present study, the irritation caused to the cervical mucosal tissue of Tibetan mini pigs following repeated administrations of different doses of POD-NLC was evaluated. In the POD-T and high-dose and medium-dose POD-NLC-treated groups, severe destruction to the cervical mucosal tissue and elevated levels of IL-1 $\beta,-6$ and -8 were observed, suggesting induction of inflammatory responses. However, the low-dose POD-NLC group did not result in any apparent pathological alteration in the mucosal epithelium. Therefore, POD-NLCs can maintain the integrity of the cervical mucosal epithelial barrier whilst also preventing an increase in the release of pro-inflammatory cytokines. The results of the present study are in agreement with previous studies, which demonstrated that the intermittent use of small doses of POD-NLCs is an efficient therapeutic method for preventing irritation of the cervical mucosal tissue (36).

E6 and E7 are oncoproteins encoded by HPV that transform cells by cooperatively targeting diverse cellular pathways involved in the regulation of cell cycle control, apoptosis and cell polarity control networks (37). Therefore, the HPV-transformed VK2/E6E7 cell line was used to investigate 
the effects of POD-NLC treatment on the viability of cells. Cytotoxic effects of POD were previously reported to influence different stages of cell cycle, including inhibition of RNA and DNA synthesis and polymerization, and prevention of cell division through inhibition of microtubule assembly (38). In a previously published study, the authors of the present study reported that POD increases the intracellular calcium concentration and upregulates the expression of $78 \mathrm{kDa}$ glucose-regulated protein homolog, glucose requlated protein 94 and calpain 2 mRNA in VK2/E6E7 cells (19). To determine the effect of POD-NLCs on VK2/E6E7 cells, proliferation inhibition rate and cytotoxicity studies were performed. The results of the present study demonstrated that more efficient inhibition of VK2/E6E7 cell proliferation was achieved following treatment with POD-NLCs compared with the POD group. POD-NLC treatment induced a proliferation inhibition rate of $>99 \%$ compared with $68.9 \%$ achieved by POD treatment. The elevated proliferation inhibition rate induced by POD-NLC treatment may be due to increased uptake of POD into VK2/E6E7 cells. In addition, compared with the POD treatment, POD-NLC resulted in increased proportion of cells in the G2/M stage and elevated apoptosis of VK2/E6E7 cells. Although the mechanism underlying these results remains to be elucidated, the observations indicate that POD-NLCs demonstrated more effective anti-HPV activity compared with free POD.

In conclusion, POD-NLCs demonstrate favorable physicochemical characteristics for transmucosal delivery, providing sustained release and controlled delivery in the cervical mucosal tissue. POD-NLCs can inhibit the growth of VK2/E6E7 cells via G2/M arrest and inhibit cell proliferation more efficiently compared with the POD. The present study demonstrated that NLCs is a promising delivery system for $\mathrm{POD}$ in the treatment of CA.

\section{Acknowledgements}

The authors of the present study would like to thank Mr. Zeng and Ms. Wang for technical assistance.

\section{Funding}

The present study was supported by the Natural Science Foundation of China (grant no. 81673067), the Natural Science Foundation of Guangdong Province (grant no. 2014A030313319) and the President Funding of Southern Medical University Nanfang Hospital (grant no. 2016C030).

\section{Availability of data and materials}

The datasets used and/or analyzed during the current study are available from the corresponding author on reasonable request.

\section{Authors' contributions}

All authors were involved in acquisition of data, analysis and interpretation of data. ZH, QL, LL were involved in revising the manuscript critically for important intellectual content. $\mathrm{YG}$ and $\mathrm{KZ}$ were involved in drafting the manuscript. $\mathrm{KZ}$ was involved conception and design of the manuscript.

\section{Ethics approval and consent to participate}

All the experimental animals and the protocol (permit number for pigs: 44002100008963) used in the present study were approved by the Experimental Animal Ethics Committee of the Southern Medical University (Guangzhou, China).

\section{Consent for publication}

Not applicable.

\section{Competing interests}

The authors declare that they have no competing interests.

\section{References}

1. Ball SL, Winder DM, Vaughan K, Hanna N, Levy J, Sterling JC, Stanley MA and Goon PK: Analyses of human papillomavirus genotypes and viral loads in anogenital warts. J Med Virol 83: 1345-1350, 2011.

2. Park IU, Introcaso $\mathrm{C}$ and Dunne EF: Human papillomavirus and genital warts: A review of the evidence for the 2015 centers for disease control and prevention sexually transmitted diseases treatment guidelines. Clin Infect Dis 61 (Suppl 8): S849-S855, 2015.

3. Lamos C, Mihaljevic C, Aulmann S, Bruckner T, Domschke C, Wallwiener M, Paringer C, Fluhr H, Schott S, Dinkic C, et al: Detection of human papillomavirus infection in patients with vaginal intraepithelial neoplasia. PLoS One 11: e0167386, 2016.

4. Fu Xi L, Schiffman M, Ke Y, Hughes JP, Galloway DA, He Z, Hulbert A, Winer RL, Koutsky LA and Kiviat NB: Type-dependent association between risk of cervical intraepithelial neoplasia and viral load of oncogenic human papillomavirus types other than types 16 and 18. Int J Cancer 140: 1747-1756, 2017.

5. Gordaliza M, Garcia PA, del Corral JM, Castro MA and Gómez-Zurita MA: Podophyllotoxin: Distribution, sources, applications and new cytotoxic derivatives. Toxicon 44: 441-459, 2004.

6. Lacey CJ, Woodhall SC, Wikstrom A and Ross J: 2012 European guideline for the management of anogenital warts. J Eur Acad Dermatol Venereol 27: e263-e270, 2013.

7. Karuppaiya $P$ and Tsay HS: Therapeutic values, chemical constituents and toxicity of Taiwanese Dysosma pleiantha-a review. Toxicol Lett 236: 90-97, 2015.

8. Deng JF, Huang CC and Lee YJ: Toxicokinetic parameters in the management of poisoning: An example of podophyllotoxin intoxication. J Toxicol Sci 23 (Suppl 2): S205-S208, 1998.

9. Karimunnisa S and Atmaram P: Mucoadhesive nanoliposomal formulation for vaginal delivery of an antifungal. Drug Dev Ind Pharm 39: 1328-1337, 2013.

10. Puglia C, Blasi P, Rizza L, Schoubben A, Bonina F, Rossi C and Ricci M: Lipid nanoparticles for prolonged topical delivery: An in vitro and in vivo investigation. Int J Pharm 357: 295-304, 2008.

11. Liu D, Liu Z, Wang L, Zhang $C$ and Zhang N: Nanostructured lipid carriers as novel carrier for parenteral delivery of docetaxel. Colloids Surf B Biointerfaces 85: 262-269, 2011.

12. Zhao J, Piao X, Shi X, Si A, Zhang Y and Feng N: Podophyllotoxin-loaded nanostructured lipid carriers for skin targeting: In vitro and in vivo studies. Molecules 21: pii: E1549, 2016.

13. Rajinikanth PS and Chellian J: Development and evaluation of nanostructured lipid carrier-based hydrogel for topical delivery of 5-fluorouracil. Int J Nanomedicine 11: 5067-5077, 2016.

14. Zhang S, Wang J and Pan J: Baicalin-loaded PEGylated lipid nanoparticles: Characterization, pharmacokinetics, and protective effects on acute myocardial ischemia in rats. Drug Deliv 23: 3696-3703, 2016

15. Wang Y, Zhao B, Wang S, Liang Q, Cai Y, Yang F and Li G: Formulation and evaluation of novel glycyrrhizic acid micelles for transdermal delivery of podophyllotoxin. Drug Deliv 23: 1623-1635, 2016.

16. Owen DH and Katz DF: A vaginal fluid simulant. Contraception 59: 91-95, 1999. 
17. Holt JD, Cameron D, Dias N, Holding J, Muntendam A, Oostebring F, Dreier P, Rohan L and Nuttall J: The sheep as a model of preclinical safety and pharmacokinetic evaluations of candidate microbicides. Antimicrob Agents Chemother 59: 3761-3770, 2015.

18. Koshiol J, Sklavos M, Wentzensen N, Kemp T, Schiffman M, Dunn ST, Wang SS, Walker JL, Safaeian M, Zuna RE, et al: Evaluation of a multiplex panel of immune-related markers in cervical secretions: A methodologic study. Int J Cancer 134: 411-425, 2014.

19. Wang Q, Han K, Li X, Xiao Y and Zeng K: Role of endoplasmic reticulum stress pathway in podophyllotoxin nanostructured lipid carriers-induced apoptosis of VK2/E6E7 cells. Nan Fang Yi Ke Da Xue Xue Bao 34: 832-836, 2014 (In Chinese).

20. D'Cruz OJ, Erbeck D and Uckun FM: A study of the potential of the pig as a model for the vaginal irritancy of benzalkonium chloride in comparison to the nonirritant microbicide PHI-443 and the spermicide vanadocene dithiocarbamate. Toxicol Pathol 33: 465-476, 2005.

21. Pachman DR, Barton DL, Clayton AC, McGovern RM, Jefferies JA, Novotny PJ, Sloan JA, Loprinzi CL and Gostout BS: Randomized clinical trial of imiquimod: An adjunct to treating cervical dysplasia. Am J Obstet Gynecol 206: 42.e1-7, 2012.

22. Fichorova RN, Mendonca K, Yamamoto HS, Murray R, Chandra $\mathrm{N}$ and Doncel GF: A quantitative multiplex nuclease protection assay reveals immunotoxicity gene expression profiles in the rabbit model for vaginal drug safety evaluation. Toxicol Appl Pharmacol 285: 198-206, 2015.

23. Olerile LD, Liu Y, Zhang B, Wang T, Mu S, Zhang J, Selotlegeng $L$ and Zhang N: Near-infrared mediated quantum dots and paclitaxel co-loaded nanostructured lipid carriers for cancer theragnostic. Colloids Surf B Biointerfaces 150: 121-130, 2017.

24. Gutierrez-Xicotencatl L, Salazar-Piña DA, Pedroza-Saavedra A, Chihu-Amparan L, Rodriguez-Ocampo AN,Maldonado-Gama M and Esquivel-Guadarrama FR: Humoral immune response against human papillomavirus as source of biomarkers for the prediction and detection of cervical cancer. Viral Immunol 29: 83-94, 2016.

25. Bestehorn K, Bestehorn M and Fleck E: Influence of different approaches of aortic valve replacement on the incidence of post-operative delirium in intermediate risk patients-a matched pair analysis. Curr Med Res Opin 31: 2157-2163, 2015.

26. das Neves J, Araújo F, Andrade F, Amiji M, Bahia MF and Sarmento B: Biodistribution and pharmacokinetics of dapivirine-loaded nanoparticles after vaginal delivery in mice. Pharm Res 31: 1834-1845, 2014.
27. Lai SK, O'Hanlon DE, Harrold S, Man ST, Wang YY, Cone R and Hanes J: Rapid transport of large polymeric nanoparticles in fresh undiluted human mucus. Proc Natl Acad Sci USA 104: 482-1487, 2007.

28. Khutoryanskiy VV: Advances in mucoadhesion and mucoadhesive polymers. Macromol Biosci 11: 748-764, 2011.

29. Ramineni SK, Dziubla TD, Cunningham LL Jr and Puleo DA: Local delivery of imiquimod in hamsters using mucoadhesive films and their residence time in human patients. Oral Surg Oral Med Oral Pathol Oral Radiol 118: 665-673, 2014.

30. Franasiak JM and Scott RT Jr: Reproductive tract microbiome in assisted reproductive technologies. Fertil Steril 104: 1364-1371, 2015.

31. Chen H, Chang X, Du D, Liu W, Liu J, Weng T, Yang Y, Xu H and Yang X: Podophyllotoxin-loaded solid lipid nanoparticles for epidermal targeting. J Control Release 110: 296-306, 2006.

32. Fichorova RN, Bajpai M, Chandra N, Hsiu JG, Spangler M, Ratnam V and Doncel GF: Interleukin (IL)-1, IL-6, and IL-8 predict mucosal toxicity of vaginal microbicidal contraceptives. Biol Reprod 71: 761-769, 2004.

33. Iwata T, Fujii T, Morii K, Saito M, Sugiyama J,Nishio H, Morisada T, Tanaka K, Yaguchi T, Kawakami Y and Aoki D: Cytokine profile in cervical mucosa of Japanese patients with cervical intraepithelial neoplasia. Int J Clin Oncol 20: 126-133, 2015.

34. Passmore JA, Jaspan HB and Masson L: Genital inflammation, immune activation and risk of sexual HIV acquisition. Curr Opin HIV AIDS 11: 156-162, 2016.

35. Ghate VM, Lewis SA, Prabhu P, Dubey A and Patel N: Nanostructured lipid carriers for the topical delivery of tretinoin. Eur J Pharm Biopharm 108: 253-261, 2016.

36. von Krogh G: Podophyllotoxin in serum: Absorption subsequent to three-day repeated applications of a $0.5 \%$ ethanolic preparation on condylomata acuminata. Sex Transm Dis 9: 26-33, 1982.

37. Peuster M,FinkC, Reckers J,BeerbaumPand von Schnakenburg C: Assessment of subacute inflammatory and proliferative response to coronary stenting in a porcine model by local gene expression studies and histomorphometry. Biomaterials 25: 957-963, 2004.

38. Sakurai H, Miki T, Imakura Y, Shibuya M and Lee KH: Metaland photo-induced cleavage of DNA by podophyllotoxin, etoposide, and their related compounds. Mol Pharmacol 40: 965-973, 1991

This work is licensed under a Creative Commons Attribution-NonCommercial-NoDerivatives 4.0 International (CC BY-NC-ND 4.0) License. 